\title{
Language as a constructor of social and cultural reality
}

\section{[Язык как конструктор социокультурной реальности]}

\author{
Albert A. Bagautdinov - Marat R. Minkin - Alexey F. Ivanov - Albina M. \\ Nizameeva
}

DOI: 10.18355/XL.2018.11.01XL.04

\begin{abstract}
Language is a unique phenomenon and the key instrument by which we can assimilate social and cultural realities of our country. Various aspects of language that consider it as a specific social-and-cultural reality and as a constructor of these realities have not been sufficiently studied yet. Linguistic-and-cultural studies which are the philosophy of language area still need a strong theoretical foundation. The purpose of this study is to explore language as a social-and-humanitarian phenomenon, interpret it as a meta-concept and constructor of reality which allows us to identify the interrelation of the language with social and humanitarian phenomena, to understand that it influences ethnicity and culture enrichment, and discuss theoretical and methodological productivity of the language. Dialectic methods and principles, as well as a method of historicism in social-and-cultural cognition, a system approach, a comparative method, interpretation analysis, elements of the structural-functional approach, conceptual modeling, an ethnomethodological approach, the phenomenological method and socio-cultural hermeneutics, were all used in the research. They allowed the authors to consider language as an integral philosophical and cultural problem. The article presents the model of the language image as a metaconcept consisting of interconnected micro-concepts, linguistic signs. It gives a philosophical interpretation of the linguistic-and-cultural concept and discusses the philosophical category of a meta-concept; distinguishes micro-concept, a linguistic sign, in the linguistic and semiotic constructor; and identifies the foundations for the linguistic-and-cultural socialization of a person and social-and-cultural reality.

Key words: language, concept, meta-concept, micro-concept, linguistic sign
\end{abstract}

\section{Аннотация}

Актуальность исследуемой проблемы обусловлена недостаточным охватом различных аспектов языка как социокультурного явления и специфической социокультурной реальности, равно как и недостаточной разработанностью в философии теоретических взглядов на язык как конструктор социокультурных реальностей, недостаточной разработанностью теоретических оснований такой молодой части науки о языке, как лингвокультурология. Цель статьи заключается в исследовании языка как социогуманитарного явления, интерпретации его как метаконцепта и «конструктора» реальности, что позволяет выявить связи языка с другими социогуманитарными явлениями, осмыслить его этнокультурообразующую функцию и теоретикометодологическую продуктивность. Ведущими методами исследования данной проблемы были диалектические методы и принципы, принципы и методы историзма в познании социокультурных явлений, системный подход, компаративный метод, метод интерпретационного анализа, элементы структурно-функционального подхода, метод концептуального моделирования, этнометодологический подход, отдельные приёмы феноменологической методологии и социально-культурной герменевтики. Эти методы позволили рассмотреть язык как целостную философскую и культурную проблему. В 
статье представлена культурософская модель образа языка как метаконцепта, состоящего из взаимосвязанных микроконцептов - языковых знаков. В работе дается философское толкование лингвокультурного концепта и вводится новая философская категория - метаконцепт; в языке, как в составном лингвосемиотическом конструкторе выделяется микроконцепт - языковой знак; выявляются лингвокультурологические основы социализации личности и конструирования социокультурной реальности.

Ключевые слова: язык, коцепт, метаконцепт, микроконцепт, языковой знак

\section{Введение}

«Лингвистический поворот» в философии середины XX века послужил отправным пунктом для построения новой гуманитарной парадигмы с фокусировкой процесса познания реальности на «текстовом его понимании». В этом ключе важным становится правильное прочтение термина и понимание феномена «язык», как специфической социокультурной реальности, направляющей «конструирование» социума и культуры на разных уровнях их организации, и одновременно как метатеоретического концепта познания. Исследование различных аспектов языка, как метатеоретического концепта в философии, может послужить успешному разрешению ряда проблем, наиболее часто возникающая из которых - фрагментарный инструментальный охват различных сторон языка как явления без взаимного учета достижений у представителей различных ветвей научного знания и философских течений, часто находящихся в оппозиции друг к другу (Galushkin, 2015; Chikhladze, 2016). При этом подобное синкретическое образование (метатеоретический концепт) не должно привести к полному слиянию образных полей, концепций языка у исследователей из различных отраслей науки.

Построением общих теорий языка занимается философия языка; специальные теории разрабатывались до XIX века в рамках философии и философской логики, затем - в оформившейся в отдельную научную дисциплину лингвистике (Stepanov, 2000).

В 90-е годы XX века в недрах социогуманитарных дисциплин возникает лингвокультурология (Maslova, 2001) имеющая своим предметом и язык, и культуру в их взаимодействии. Многие понятия этой области знания еще недостаточно освещены в научной литературе и вызывают полемику в работах ученых. Настоящее исследование, опираясь на мощный социгуманитарный аппарат, лингвистическую и философскую базу восполняет пробел отсутствия философских оснований лингвокультурологии.

Исследование языка в социально-культурном контексте при помощи философского категориального аппарата позволяет рассматривать язык не просто как концепт, виртуальную смысловую единицу, отражающую желаемую и ожидаемую реальность, а как метаконцепт, выражающий реальность существующих феноменов синхронной целостности культурных объектов, обогащающую процесс познания.

Под языком, как метаконцептом (Bagautdinov, 2006, 2010), в работе будет пониматься такое общенаучное понятие, которое имеет смысл на общетеоретическом уровне процесса познания и фиксирует такую реальность, под которой имеется в виду онтологическое бытие-в-себе, т.е. в-себе-бытие, абстрагированное от его рефлектированности, выводимой из познавательной связи, в некоторой степени синонимическое «миру» понятие, которое в классическом толковании наименовалось бы «мир [языка]». Эта реальность по аналогии с окружающим миром будет по-разному интерпретироваться исследователями с разными мировоззренческими ориентирами, для идеалистов «лингвистическая реальность» будет находиться где-то посередине «мира вещей» и «мира идей», или, возможно, сливаться с миром идей, а у сторонников 
«линии Демокрита» язык мог бы выступить в качестве «материи» культуры, состоящей из «атомов»- знаков, в античной интерпретации.

Всестороннее осмысление языка и рассмотрение основных особенностей данного феномена, его теоретико-методологической «продуктивности» должно существенно облегчить анализ социальных и культурных процессов, протекающих в том или ином обществе, культуре и в современном научном познании.

Совмещение "лингвистического" и "культурного", предпринятое в работе открывает перспективные возможности в дальнейших исследованиях по данной проблеме в социолингвистике и, особенно, социосемиотике, универсализации механизмов ритуализации социальной жизни в культур-социологии и лингвокультурологии.

Интерес к проблеме философского анализа образа языка обусловлен тем, что окружающая нас действительность презентует себя человеку в виде знаков, являющихся минимальными носителями информации о мире. Диада «язык и человек» оказалась в центре интересов наук о знаковых системах, которые рассматриваются теперь как кристаллизация практического опыта, накопленного в рамках исторически сложившейся общности.

Знаковость - присущая познанию природного и социального мира особенность, которая находит яркое выражение в языке, как социокультурном феномене (Taisina, 2003). Однако изучение природного или социального не ограничивается только изучением природных или социальных знаков. Интерпретация знаков, вернее, философская интерпретация - это еще одна особая область исследования, также связанная с языком (Shakirov, 2004) .

На взгляд автора, наиболее перспективное рассмотрение языка как социогуманитарной проблемы возможно при помощи ренессанса достижений концептуализма (Abelar, 2010) в немистифицированном, а в академическом варианте (Abelar, 2010). Такой подход к языку подразумевает его интерпретацию как метатеоретического концепта и одновременно как конструктора социокультурной реальности, творческие аспекты которого реализуются в виде исторически сложившихся форм сложного символического коммуникационного поведения, упорядоченной системы действий; выражающих определенные социальные и культурные взаимоотношения, ценности.

\section{Теоретический дискурс}

Проблема языка в социогуманитарном познании разрабатывается уже долгое время, априорно онтологический статус языка, по сути, был зафиксирован в древних религиозных писаниях (Dyachenko, 1993; Mechkovskaya, 1998; Fasmer, 2004) но, вплоть до середины XX в. «лингвоцентризм» выражается нечетко. Начало философского осмысления языка можно уверенно вести, по крайней мере, со спора о происхождении языка «по природе», physei, или «по установлению», thesei. Это был метафизический язык Платона-Аристотеля с универсальным континуумом смыслов (Bagautdinov, 2010; Lebedev, 2008: 97). Данная линия получила название «аристотелизм» (Mauro, 2000).

«Неопределенность» в исследовании языка имела место в виду преобладания эмпирического в разработке его, как социогуманитарной проблемы, что было обусловлено теологической спецификой социальных установок исследователей на ранних этапах развития социума и культуры в Античности и Средневековье, особенностью философского дискурса, метафизически замкнутого и однообразного вплоть до средины XX века, общенаучными философскими тенденциями, характерными для эпохи постмодернизма.

XLinguae, Volume 11 Issue 1XL, January 2018, ISSN 1337-8384, eISSN 2453-711X 
Прорыв из «парадигмы замкнутости» философии по отношению к естественному языку был совершен при обрушении фундаментальной онтологической идеи классической метафизики, идеи субстанции. Тогда философия становиться более многообразной, в недрах философских дисциплин проявляется интерес к семиотическому строению культуры и ее реалий.

Во второй половине XX века происходит знаменитый «лингвистический поворот» западноевропейской философии, который связывается с именем Л. Витгенштейна (Wittgenstein, 2011). В первый период творчества он изучал язык науки, но во второй период творчества перешел к исследованию естественного разговорного человеческого языка (Korolev, 2003).

В своей концепции языка как образа мира Л. Витгенштейн (Wittgenstein, 2011) через соотнесение грамматики и логики преодолевает аностицизм «лингвистической относительности». Действительные философские открытия «Логико-философского трактата» связаны с теми гносеологическими, онтологическими и методологическими выводами, которые были сделаны на основе осмысления нового статуса логики в процессе изучения взаимосвязей языка и познания. Л. Витгенштейн (Wittgenstein, 2011) разработал аристотелевскую образную теорию языка, то есть языка, отображающего действительность. У Л. Витгенштейна (Wittgenstein, 2011; Korolev, 2003) язык и мир стоят друг к другу в том же внутреннем образном отношении, которое имеет место между граммофонной записью, музыкальной мыслью и партитурой. Они имеют общую логическую структуру и проекции.

Подобное направление философской мысли могло вернуть онтологической картине мира связность через обращение к пространству языка. Здесь язык понимается уже в качестве универсального парафеномена, самостоятельно продуцирующего и эксплицирующего свое содержание. Наиболее показательна в этом отношении позиция М. Хайдеггера (Haidegger, 1997), который, интерпретируя язык как «дом бытия», оборачивает традиционное для метафизики понимание отношения «мысль-язык». Для него язык есть не столько инструмент, обслуживающий мысль, сколько мысль есть способ, которым актуализируются изначальные («первоначальные») смыслы, содержащиеся в языке (Korolev, 2003).

Релятивистские подходы к языку конца XX века привели к широкому признанию конвенциональной, знаковой его природы, и «классики постмодернизма», такие как Ж. Делез (Deleuze, 2011), М. Фуко (Foucault, 1994), Ж. Деррида (Derrida, 2000), Р. Барт (Barthes, 1989), и другие, долгое время обсуждали агрессивный, диктаторский характер языка. У подавляющего большинства представителей постмодернистской мысли наблюдается направленность к работе на «верхних этажах» языковой реальности (Korolev, 2003; Stepanov, 2000; Cassirer, 2001; Searle, 1995). Язык берется и рассматривается: а) в его реальном функционировании как нечто уже ставшее и унаследованное; б) как речевая практика; в) как форма власти (Orwell, 2005); г) как бытие бессознательного; д) как потенциальность и возможность его смысловой инаковости.

Оформившийся в результате «лингвистического поворота» философский интерес к языку должен был неизбежно прийти к необходимости универсализации понимания этого феномена. Это должно было привести и привело к анализу образа языка, как творческой социокультурной силы, способной «конструировать» жизненный мир человека.

\section{Методы исследования}

В процессе исследования были использованы следующие методы: диалектические принципы всеобщей связи и развития, принцип восхождения от абстрактного к конкретному, принцип единства анализа и синтеза, субъекта и объекта, принципы и методы историзма в познании социокультурных явлений, 
системный подход, компаративный метод, метод интерпретационного анализа, элементы структурно-функционального подхода, метод концептуального моделирования, этнометодологический подход, отдельные приёмы феноменологической методологии и социально-культурной герменевтики. Для решения исследовательских задач диссертации существенное значение имела структурно-семиотическая методология.

\section{Результаты и их обсуждение}

Наиболее полное понимание концептуальной сущности языка, как конструктора социокультурной реальности и метаконцепта культуры, содержащего в себе конвенцоинальное бытие явлений, можно найти в «Теории коммуникативного действия» Ю. Хабермаса (Habermas, 2001), и в трудах автора «Теории интенциональности» Дж. Серля (Searle, 1995, 2002).

Невидимая структура социокультурной реальности создает некоторую проблему целостного восприятия процесса «конструирования» действительности. Ряд особенностей мира зависят от людей (институциональные факты), часть свойств мира существует вне зависимости от сознания человека, поэтому процесс созидания образа реальности требует обще употребляемых символов, передающих также и социальный опыт (культурные нормы, традиции, естественнонаучное и технологическое знание), и связывающие людей в группы. Подобное «связывание» объясняется в современной науке теорией коммуникации.

Системообразующим и структурирующим общественность элементом теории коммуникативного действия является концепт речевого действия, который может быть определен в виде «акта консенсуса», посредством которого говорящий хочет договориться с кем-либо другим относительно чего-либо (Farman, 1999). Чтобы коммуникация могла заниматься сама собой, она должна быть достаточно сложной, в части объединения людей в страты, микро и макро социальные группы - многоступенчатой.

Язык формирует то предпонимание, которое человек получает в свое распоряжение в ходе обучения, использует в качестве базиса для первичного осмысления мира. В процессе языковой социализации происходит формирование личностной и групповой идентичности, вырабатывается формальный концепт мира, т.е. основные понятия, которые регулируют практическую деятельность людей и обусловливают возможность познания мира и детализации его образа в индивидуальном и общественном сознании.

Социальность, проявляющаяся как отношение людей по поводу вещей и людей, не ассимилируется генами. Люди используют внебиологические средства воспроизведения социальности в смене поколений. Языковой знак есть своеобразная наследственная сущность внебиологического социального кодирования, обеспечивающая трансляцию всего, что необходимо обществу, но не может быть передано по биокоду, становление языковой личности нельзя представлять как однонаправленное движение. Разные его периоды характеризуются различными доминантами, определяющими речевое поведение. Языковую эволюцию личности в период раннего детства определяет имитационный комплекс, на основе которого формируются протознаковые элементы коммуникации (кинетические, голосовые и др.). Интериоризация невербально-имитационных иконических протознаковых форм закладывает основу новых явлений в детском речевом становлении: она становится базисом возникновения символической (семиотической) функции. Черпая материал из речи окружающих, ребенок активно и творчески созидает свое поначалу еще несовершенное языковое здание. Стремясь вычленить слова в речевом потоке, малыш постигает характер фонологических оппозиций, развивает свой XLinguae, Volume 11 Issue 1XL, January 2018, ISSN 1337-8384, eISSN 2453-711X 
фонематический слух. На основе фонематического восприятия формируются грамматические парадигмы каждого морфологического класса. Прислушиваясь к речи взрослых, ребенок открывает законы образования слов, на основе выделения словообразовательных сверхмоделей пополняет свой словарь и т.д. Овладение языковой структурой определяет направление коммуникативного развития ребенка от рождения до возраста 5-6 лет. Переступив барьер первичной языковой социализации, личность становится обладателем языкового механизма, своего рода персонального компьютера, который открывает человеку новые когнитивно-коммуникативные возможности (Sedov, 1999).

Сознание человека оказывается полностью включенным в язык. Более того, сознание и есть язык: («языковое сознание»). В свою очередь и мышление оказывается языковым («языковое мышление»). Соответственно и личность обрисовывается как языковая («языковая личность»). Языковая личность становится своеобразной динамической совокупностью огромного опыта, накопленного благодаря коллективному действованию в реальной и коммуникативной действительности, и в действительности невербального мышления.

Процесс онтогенетической эволюции языковой личности после завершения ею стадии самонаучения языку как системе выражается в становлении способности homo loquens к порождению и пониманию текстов. Структуры языка (схемы классификации), позволяющие различать объекты подчиняют себе индивида, происходит формирование высказывания, действия и высказывания существования, мир разделяется на эоны (интимность, удаленность) через выбор личного местоимения происходит принуждение высказывать свое отношение к другому (Я и ты). В языке воплощаются начала объективности. Формы человеческого поведения связаны с разнообразными стереотипами вербальных текстов.

Важным пунктом «Теории коммуникативного действия» является утверждение о нередуцируемой собственной структуре человеческой коммуникации. Коммуникативная компетенция, также как и лингвистическая, имеет универсальное ядро. Оно включает в себя фундаментальную систему правил, которой обладает для успешного преобразования предложений в выражения взрослый говорящий. На изучении этих всеобщих структур возможных речевых ситуаций сосредоточена универсальная прагматика или теория коммуникативной компетенции. Такая компетенция становиться возможной на этносоциальном уровне (Soboleva, 2005; Farman, 1999).

Последующее освоение культуры и ее воспроизводство происходит в диалоге смыслов, посредством общения и взаимодействия людей. Общаясь с другими людьми в процессе комуникации, человек усваивает знания, накопленные человечеством, его опыт, установившиеся законы и нормы, ценности и способы деятельности, формируется как личность. Общество и язык продолжают формировать человека на нем говорящего при помощи конфигурации идей, заключенных в значении его слов в процессе познания на протяжении всей жизни, влияя на концептуализацию мира.

1. Лингвокультурную сущность языка может быть интерпретирована эмпирически и теоретически в виде концепта и метаконцепта - многомерных ментальных единиц, включающих в себя понятийный, образный и ценностный компоненты, обладающих способностью быть опредмеченными в разнообразной языковой форме. Концепт - единица коллективного знания/сознания, отправляющая к высшим духовным ценностям и имеющая языковое выражение, отмеченное социокультурной спецификой.

Учение о концепте восходит к средневековому теологу П. Абеляру (Abelar, 2010), который понимал его как интерпретацию библейских откровений (Abelar, 2010). 
Концепт является продуктивной категорией наук филологического толка, среди которых можно выделить близкую нам лингвокультурологию (Maslova, 2001).

В протерминологической функции конщепт стал активно употребляться в лингвистической литературе с начала 90-х годов $\mathrm{XX}$ века. лингвокультурологическое насыщение этой лексемы продолжила статья акад. Д.С. Лихачева (Likhachev, 1997) о концептосфере русского языка. Пересмотр традиционного логического содержания концепта и его психологизация объясняются, в том числе, и потребностями когнитологии, в частности, когнитивной лингвистики, фокусирующей внимание на соотнесении лингвистических данных с психологическими, для которой оперировать категорией понятия в классическом, «безо́бразном» представлении было явно недостаточно.

С точки зрения различных подходов (семантического, культурологического, психологического, логико-понятийного и т.д.) концепты рассматриваются как ментальные способы репрезентации действительности в сознании людей, как "сгустки смысла", несущие важную культурную информацию и находящие свое конкретное выражение в виде знаков (в широком понимании знака): в языке, в искусстве и т.д.

Концепты - мыслительные единицы человеческого сознания. Оязыковление концептов в разных социумах избирательно, что обусловлено их культурнопсихологической релевантностью, системой ценностей кодирующих их людей. В отличие от понятий они - более широкое явление. Помимо понятия концепты включают в себя ценностный и, как правило, образный компоненты (Karasik, 2001).

Несмотря на довольно широкий спектр социогуманитарных исследований концепта (этнических особенностей, профессионально-лексической и аксиологической окраски и т.д.) среди лингвокультурологов в настоящее время не достигнут консенсус в плане детального определения и соотношения его сущностных свойств.

В нефилософском понимании концепта наметилось три основных подхода. Вопервых, в самом широком смысле в число концептов включаются лексемы, значения которых составляют содержание национального языкового сознания и формируют «наивную картину мира» носителей языка. Совокупность таких концептов образует концептосферу языка, в которой концентрируется культура нации. Определяющим в таком подходе является способ концептуализации мира в лексической семантике, основным исследовательским средством концептуальная модель, с помощью которой выделяются базовые компоненты семантики концепта и выявляются устойчивые связи между ними. В число подобных концептов попадает любая лексическая единица, в значении которой просматривается способ (форма) семантического представления. Во-вторых, в более узком понимании к числу концептов относят семантические образования, отмеченные лингвокультурной спецификой и тем или иным образом характеризующие носителей определенной этнокультуры (Vorkachev, 2001). Совокупность таких концептов не образует концептосферы в виде целостного и структурированного семантического пространства, но занимает в ней определенную область - концептуальную. Также к числу концептов относят лишь семантические образования, список которых в достаточной мере ограничен и которые являются ключевыми для понимания национального менталитета как специфического отношения к миру его носителей.

Метаконцепт - обобщенное философское понятие, связанное с речью и охватывающее пространство человеческого сознания. Метаконцепт предельно субъектен и направлен на другого субъекта - своего идеального слушателя или

XLinguae, Volume 11 Issue 1XL, January 2018, ISSN 1337-8384, eISSN 2453-711X 
читателя, в ответах на вопросы которого актуализируются смыслы высказывания и переживания времени и пространства (Bagautdinov, 2007, 2010). 2. Микроконцепт в лингвосемиотическом смысле является наиболее приемлемой кондоминирующей категорией, раскрывающей лингвокультурную сущность языкового знака. Понимание знаковости в языке как свойства, присущего предметам и явлениям социокультурной действительности выявляет проблему конструирования социокультурной реальности на «атомарном» уровне языка. Языковой знак сочетает в себе на микро уровне концептуальную сущность языка и его манифестацию. В системной совокупности языковой знак «конструирует» язык, соединяющий наименования явлений действительности с символьным отображением и их интерпретацией в языковом коллективе.

3. Обращение к языку, отражающему реально существующий феномен целостности культурных явлений, фактор их смысловой синхронности, обеспечивающий единство культуры, изначально присутствовавало в духовной культуре человечества. Современное социокультурное понимание творческих аспектов языка осмысливается в виде разнообразных лингвокоммуникативных ритуалов, «конструирующих» социокультурные реальности.

\section{Заключение}

В процессе исследования было установлено, что человеческая культура обращалась к проблеме языка, начиная с архаичной и с более развитий религиозной культуры как к своему онтологическому и нерефлексируемому основанию. В Новое время образ язык начинает фигурировать в культуре чаще в качестве эпистемологического инструментария для «препарирования» открывающегося взорам мира. В культуре XX-XXI веков образ языка начинает уже рассматриваться как самоцель для детального изучения и как особое бытие, называемое автором понятием метаконцепт. Эта реальность языка гносеологически первый образ выстраиваемого человеком и обществом мира, социокультурная «языковая пленка», состоящая из «культурных атомов» языковых знаков, называемых автором «микроконцепты». Каждый уровень социокультурных взаимодействий имеет основанием свои модели-«слепки» концепты структурирования индивидуального, этносоциального и других социокультурных образований личностной идентичности человека.

Социокультурная иституализация происходит в недрах конституирования, иерархизации-деиерархизации концептов.

Концепты - единицы коллективного знания/сознания, отправляющие к высшим духовным ценностям, могут быть выражены с помощью языка, отмечены социокультурной спецификой.

Сочетание, иерархизация концептов дают тот или иной промежуточный тип (модус) личностной идентичности, объединение подобных модусов средствами линвокоммуникативных ритуалов выступает основанием конституирования того или иного типа общества (языковой коллектив, социокультурные образования более высокого порядка). Лингвоконструирование - процесс индивидуальный и социальный, вертикальный и горизонтальный, потенциально незавершенный и открытый и протекает на протяжении всей жизни человека

\section{Bibliographic references}

ABELAR, P. 2010. Theological treatises. Translated from the Latin by S. Neretina. Moscow: Canon +. ROI Rehabilitation. ISBN: 978-5-88373-183-X

BAGAUTDINOV, A.A. 2006. Language as a meta-theoretical concept and constructor of sociocultural reality. PhD Thesis. Kazan: KSTU.

BAGAUTDINOV, A.A. 2010. Language as a meta-theoretical concept and constructor of sociocultural reality: monograph. Voronezh: VSPU. - ISBN 978-588519-665-9 
BARTHES R., 2008. Writing Degree Zero. Translated from French by G.K. Kosikova. Moscow: Academic Project. ISBN 978-5-8291-0897-7.

CASSIRER, E. 2001. Philosophy of symbolic forms. In 2 volumes. In: Language, vol. 1. Moscow - Saint Petersburg: University Book. ISBN 5-7914-0023-3

CHIKHLADZE, L. 2016. The elements of centralization in municipal systems of foreign countries. Comparative legal analysis. In: Bulletin of the Georgian National Academy of Sciences, vol. 10, n. 2, pp. 178-181. ISSN, 01321447.

DELEUZE, G. 2011.The Logic of Sense. Translated from French by J.I. Svirsky. Moscow: Academical Project ISBN 978-5-8291-1251-6.

DERRIDA J. 2000. Of Grammatology. Translated from French by N. Avtonomova. Moscow: Ad Marginem. ISBN 5-93321-011-0

DYACHENKO, G. 1993. Complete Church Slavonic Dictionary. Moscow: TipoLiterografiya I. Efimova. ISBN 5-87301-068-4

FARMAN, I.P. 1999. Social and cultural projects of Jurgen Habermas. Moscow: IFRAN. ISBN 5-201-02016-X

FASMER, M. 2004 Etymological dictionary of the Russian language: In 4 vol. T.4. Moscow: AST. pp.550-551. ISBN 5-17-018550-2 (AST) ISBN 5-271-05484-5 (Astrel)

FOUCAULT, M. 1994. The Order of Things: An Archaeology of the Human Sciences. Translated from French by V.P. Vizgin, N.S. Avtonomova. Saint Petersburg: A-cad. ISBN 5-85962-021-7.

GALUSHKIN, A. 2015. Internet in modern Russia: History of development, place and role. In: Asian Social Science, vol. 11, n. 18. pp. 305-310. ISSN 1911-2017 (Print) ISSN 1911-2025 (Online).

HABERMAS J. 2001. Moral Consciousness and Communicative Action. Translated from the German by D.V. Sklyadnev. Saint Petersburg.: Science. ISBN 5-02-0268100 .

HAIDEGGER M. 1997. Being and Time. Translated from the German by V.V. Bibikhin. Moscow: AD MARGINEM ISBN 5-8805-021-6.

KARASIK, V.I. 2001. On the categories of linguoculturology. Language personality: problems of communicative activity. Volgograd: Change. ISBN 5-93423-003-4.

KOROLEV, K. 2003. Languages as an image of the world. Moscow: AST. ISBN 517-019254-1 (AST) ISBN 5-7921-0648-7 (Terra Fantastica)

LEBEDEV, M.V. 1997. Philosophical grounds for the stability of linguistic meaning. PhD Thesis. Moscow. IF RAS.

LEBEDEV, M.V. 2008. Stability of linguistic meaning monograph. Moscow: LKI. ISBN 978-5-382-00917-9

LEWIS, K.S. 2008. The Chronicles of Narnia: Fairy Tales. Moscow: Eksmo: Contact Media Group. ISBN 978-5-89573-934-9

LIKHACHEV, D.S.1997. Conceptosfera of the Russian language. Russian Literature. From the theory of literature to the structure of the text. Moscow: Academia. ISBN: 5874440453

MASLOVA, V.A. 2001. Lingvokulturologiya. Moscow: Publishing Center "Academy". ISBN 5-7695-0745-4

MAURO, T. 2000. Introduction to semantics. Translated by B.P. Narumova. Moscow: House of the intellectual book. ISBN 5-7333-0045-0.

MECHKOVSKAYA, N.B. 1998. Language and religion. Lectures on philology and history of religions. Moscow: FAIR. ISBN 5-88641-097-X.

ORWELL G. 2005. Novel. Translated from the English by V.Golysheva. Saint Petersburg: Classical alphabet. ISBN 5-352-01296-4

SEARLE, J. 2002. Opening consciousness again. Trans. with English. A.F. Gryaznova. Moscow: Idea-Press. ISBN: 5-7333-0038-8 
SEARLE, J.R. 1995. The Construction of Social Reality. New York: Free Press. ISBN: 0684831791

SEDOV, K.F. 1999. Formation of the structure of oral discourse as an expression of the evolution of the language personality. PhD Thesis. Saratov: SSU named by N.G. Chernishevsky.

SHAKIROV, I.A. 2004. Dialectics of arbitrary and involuntary in the procedure of social interpretation. PhD Thesis. Kazan: KSU.

SOBOLEVA, M.E. 2005. Philosophy as a "criticism of the language" in Germany. St. Petersburg: St. Petersburg. University. ISBN: 5-288-03691-8

STEPANOV, Y.S. 2000. Semiotics: anthology. Moscow: Academic project. ISBN: 588687-096-2

TAISINA, E.A. 2003. Philosophical questions of semiotics. Kazan: Kazan State Power Engineering University. ISBN 5-89873-096-6

VORKACHEV S.G. 2002. Methodological Foundations of Linguo-Conceptology. In: Theoretical and Applied Linguistics, n. 3, pp. 79-95. ISSN 0130-9730

WITTGENSTEIN L. 2011. Tractatus Logico-Philosophicus. Moscow: Canon + Rehabilitation. ISBN 978-5-88373-116-6

Words: 3831

Characters: 32246 (17,91 standard pages)

Assoc. Prof. Albert A. Bagautdinov, PhD.

Department of Humanitarian Education and Sociology

Almetyevsk State Oil Institute

2 Lenin street,

423450 Almetyevsk,

Russia

abagautdinov@yandex.ru

Assoc. Prof. Marat R. Minkin, PhD.

Department of Humanitarian Education and Sociology

Almetyevsk State Oil Institute

2 Lenin street,

423450 Almetyevsk,

Russia

marat73mr@mail.ru

Assoc. Prof. Alexey F. Ivanov, PhD.

Department of Informatics and Mathematics

Almetyevsk State Oil Institute

2 Lenin street,

423450 Almetyevsk,

Russia

1_prorektor@agni-rt.ru

Assoc. Prof. Albina M. Nizameeva, PhD.

Department of Foreign Languages

Almetyevsk State Oil Institute

2 Lenin Street,

423450 Almetyevsk,

Russia

lina.saveleva.99@mail.ru 